\title{
Lower Monoamine Oxidase-A Total Distribution Volume in Impulsive and Violent Male Offenders with Antisocial Personality Disorder and High Psychopathic Traits: An [ $\left.{ }^{1} \mathrm{C}\right]$ Harmine Positron Emission Tomography Study
}

\author{
Nathan J Kolla ${ }^{1,2,3,4}$, Brittany Matthews ${ }^{1,2}$, Alan A Wilson ${ }^{1,2,3}$, Sylvain Houle ${ }^{1,2,3}$, R Michael Bagby ${ }^{1,2,3,5}$, \\ Paul Links ${ }^{4,6}$, Alexander I Simpson ${ }^{3}$, Amina Hussain ${ }^{1,2}$ and Jeffrey H Meyer*, ${ }^{*, 2,3,4}$ \\ 'Centre for Addiction and Mental Health (CAMH) Research Imaging Centre, Toronto, Ontario, Canada; ${ }^{2}$ Campbell Family Mental Health Research \\ Institute, CAMH, Toronto, Ontario, Canada; ${ }^{3}$ Department of Psychiatry, University of Toronto, Toronto, Ontario, Canada; ${ }^{4}$ Institute of Medical \\ Science, University of Toronto, Toronto, Ontario, Canada; ${ }^{5}$ Department of Psychology, University of Toronto, Toronto, Ontario, Canada; ${ }^{6}$ Department \\ of Psychiatry, University of Western Ontario, Toronto, Ontario, Canada
}

Antisocial personality disorder (ASPD) often presents with highly impulsive, violent behavior, and pathological changes in the orbitofrontal cortex (OFC) and ventral striatum (VS) are implicated. Several compelling reasons support a relationship between low monoamine oxidase-A (MAO-A), an enzyme that regulates neurotransmitters, and ASPD. These include MAO-A knockout models in rodents evidencing impulsive aggression and positron emission tomography (PET) studies of healthy subjects reporting associations between low brain MAO-A levels and greater impulsivity or aggression. However, a fundamental gap in the literature is that it is unknown whether brain MAO-A levels are low in more severe, clinical disorders of impulsivity, such as ASPD. To address this issue, we applied [ ' $\mathrm{C}]$ harmine PET to measure MAO-A total distribution volume (MAO-A $\vee_{T}$ ), an index of MAO-A density, in 18 male ASPD participants and 18 age- and sex-matched controls. OFC and VS MAO-A $V_{T}$ were lower in ASPD compared with controls (multivariate analysis of variance (MANOVA): $F_{2,33}=6.8, P=0.003$; OFC and VS MAO-A $V_{T}$ each lower by $19 \%$ ). Similar effects were observed in other brain regions: prefrontal cortex, anterior cingulate cortex, dorsal putamen, thalamus, hippocampus, and midbrain (MANOVA: $F_{7,28}=2.7, P=0.029$ ). In ASPD, VS MAO-A $V_{T}$ was consistently negatively correlated with self-report and behavioral measures of impulsivity $(r=-0.50$ to -0.52 , all P-values $<0.05$ ). This study is the first to demonstrate lower brain MAO-A levels in ASPD. Our results support an important extension of preclinical models of impulsive aggression into a human disorder marked by pathological aggression and impulsivity.

Neuropsychopharmacology (2015) 40, 2596-2603; doi: 10.1 1038/npp.20 I5. I06; published online 29 July 2015

\section{INTRODUCTION}

The vast majority of violent crime is perpetrated by a small group of males who exhibit conduct-disordered behavior from childhood onward and fulfill diagnostic criteria for antisocial personality disorder (ASPD) as adults (Moffitt et al, 2002). Pathological impulsivity is a core symptom of ASPD (Swann et al, 2009) that relates to the aversive behaviors and comorbidities associated with the disorder, including violent offending (Zhou et al, 2014) and alcohol dependence (AD) (Rubio et al, 2008). There are very few molecular imaging studies of ASPD and, to the best of our knowledge, no abnormalities are identified from postmortem

*Correspondence: Dr $H$ Meyer, Centre for Addiction and Mental Health Research Imaging Centre, 250 College St, Toronto, Ontario M5T IR8, Canada, Tel: + I 4I6 535 850I, Fax: + I 4169794656 , E-mail: jeff.meyer@camhpet.ca

Received 30 October 2014; revised 9 March 2015; accepted 10 March 2015; accepted article preview online 17 June 2015 investigations in clinically diagnosed individuals with the condition, although brain phenotypes such as low orbitofrontal cortex (OFC) $5-\mathrm{HT}_{2 \mathrm{~A}}$ receptor binding in impulsive males with ASPD (Meyer et al, 2008; Rylands et al, 2012) and increased amphetamine-induced nucleus accumbens dopamine release in humans with high impulsive-antisocial psychopathic traits (Buckholtz et al, 2010) have been reported. However, low brain monoamine oxidase-A (MAO-A), an enzyme localized to outer mitochondrial membranes that metabolizes amine neurotransmitters implicated in aggressive behavior (Bortolato et al, 2008), has emerged as a promising molecular target.

Multiple tiers of evidence from preclinical and clinical studies support a strong relationship between low or absent MAO-A and impulsive aggression. First, males with a rare point mutation in the eighth exon of the MAO-A gene leading to complete and selective deficiency of MAO-A exhibit severely impulsive and aggressive behavior (Brunner et al, 1993). Second, positron emission tomography (PET) studies of healthy humans that used MAO-A-selective 
radiotracers found inverse relationships between MAO-A binding in several brain regions and self-reported anger, aggression, and hostility (Alia-Klein et al, 2008; Soliman et al, 2011). Third, targeted knockout of MAO-A in mouse embryonic stem cells produces impulsively aggressive adult mice (Cases et al, 1995; Scott et al, 2008). Fourth, pharmacological inhibition of MAO-A during murine embryogenesis increases impulsive aggression on pharmacologic challenge in adult mice (Mejia et al, 2002). Fifth, MAO-A genetic polymorphisms that are associated with lower MAO-A transcription in cell lines have been found to interact with childhood adversity to increase the risk of adult violent convictions (Caspi et al, 2002). However, it has never been empirically determined whether brain MAO-A is lower in violent and clinically impulsive populations. To address this critical issue, the principal aim of the study was to measure $\mathrm{MAO}-\mathrm{A}$ total distribution volume $\left(\mathrm{MAO}-\mathrm{A}_{\mathrm{T}}\right)$, an index of MAO-A level, in the brains of highly impulsive, violent offenders with ASPD.

$\left[{ }^{11} \mathrm{C}\right]$ Harmine is a PET radiotracer ideally suited to measure MAO-A level, because it is reversible, selective for the MAO-A isoenzyme, and binds with high affinity to the substrate cavity in the center of the MAO-A enzyme (Son et al, 2008). Lower MAO-A levels are associated with lower MAO-A activity in the brain (Saura et al, 1992).

We hypothesized that MAO-A $\mathrm{V}_{\mathrm{T}}$ would be lower in the OFC and ventral striatum (VS) of ASPD with impulsive violence and that OFC and $\mathrm{VS}$ MAO-A $\mathrm{V}_{\mathrm{T}}$ would vary inversely with measures of impulsivity. The OFC and VS were chosen as the main regions of interest (ROI), because they show consistent functional and/or biological abnormalities in ASPD and aggressive behavior (Blair, 2004; Buckholtz et al, 2010; Glenn and Yang, 2012; Meyer et al, 2008; Rylands et al, 2012) and are key structures in the neural circuitry mediating impulsivity (Dalley et al, 2011).

\section{MATERIALS AND METHODS}

\section{Participants}

Thirty-six males completed the study protocol: 18 participants with ASPD and 18 control participants without ASPD. Each participant provided written consent following explanation of study procedures. All study components were approved by the Research Ethics Board for Human Subjects at the Centre for Addiction and Mental Health, Toronto, Canada.

\section{ASPD Subjects}

ASPD participants were recruited from the community and probation services. ASPD participants were clinically assessed by a forensic psychiatrist (NJK) and diagnosed using the Structured Clinical Interview for DSM-IV Axis II, Personality Disorders (SCID II) (First et al, 1997), and the Structured Clinical Interview for DSM-IV-TR Axis I Disorders (SCID I) (First et al, 2002). Each ASPD participant had a history of impulsive violent offending that included assault, sexual assault, robbery, uttering threats, and manslaughter. Exclusion criteria included history of a psychotic, major depressive, or bipolar disorder and current drug abuse or dependence. Psychotropic medication use was also exclusionary. Sixty-seven percent of the ASPD sample had no lifetime exposure to psychotropic medication: four subjects had brief exposures to psychostimulants as children but had not taken psychotropic medication as adults. One subject received intermittent treatment with an atypical antipsychotic to manage acute aggression while previously incarcerated but had not been treated in over 5 years. Another subject was taking clonazepam intermittently until 2 months prior to study enrollment. Nine subjects additionally met criteria for current $\mathrm{AD}$.

\section{Control Subjects}

Control subjects consisted of nine males with $\mathrm{AD}$ and nine subjects without $\mathrm{AD}$. ASPD subjects were matched to controls based on the presence or absence of $\mathrm{AD}$ comorbidity, given the association of $\mathrm{AD}$ with global alterations of brain MAO-A V $\mathrm{T}_{\mathrm{T}}$ (Matthews et al, 2014). Therefore, we included controls with $\mathrm{AD}$ to optimize matching. Control subjects without AD were screened with the SCID I and SCID II by an experienced rater and verified by review with a psychiatrist (JHM). These subjects had no history of psychiatric illness and had not endorsed conduct disorder symptoms as children or youth. Control subjects with AD were also screened with the SCID I and SCID II, which was verified by a psychiatrist (JHM). This subset of controls had no lifetime history of additional psychiatric illness, including ASPD. One AD subject had been treated with diazepam for alcohol withdrawal 15 years prior to his involvement in the study. None of the other control participants had any previous psychotropic medication exposure. Control subjects were age-matched within 4 years to the ASPD participants.

Control subjects formed a subset of participants from previously published studies in our laboratory (Matthews et al, 2014; Soliman et al, 2011). None of the study subjects was a current smoker: $38.9 \%$ of the ASPD subjects and $33.3 \%$ of the control subjects were past smokers $(P=1.0$, two-tailed Fisher's exact test). Non-smoking status was verified in the ASPD and AD control subjects by self-report and breathalyzer testing for carbon monoxide (MicroSmokerlyzer; Bedfont Scientific, Kent, United Kingdom) and by selfreport in the healthy control subjects. All subjects provided negative urine drug screen tests on assessment and PET scanning days. Study subjects refrained from the use of tea, coffee, or caffeinated beverages on the day of PET scanning.

\section{Image Acquisition}

Participants underwent a single $\left[{ }^{11} \mathrm{C}\right]$ harmine PET scan. 370 $\mathrm{MBq}$ of intravenous $\left[{ }^{11} \mathrm{C}\right]$ harmine was administered as a bolus at the beginning of each PET scan. An automatic blood sampling system (Model PBS-101, Comecer Netherlands, Joure, the Netherlands) measured arterial blood radioactivity continuously for the first $22 \mathrm{~min}$. Following bolus injection, manual samples were obtained at 2.5, 7.5, 15.0, 20.0, 30.0, $45.0,60.0$ and $\sim 90.0 \mathrm{~min}$. Whole-blood and plasma radioactivity was measured as previously reported (Ginovart et al, 2006). Plasma analysis of $\left[{ }^{11} \mathrm{C}\right]$ harmine used column capture and switching methods (Hilton et al, 2000). Whole, unadulterated plasma was injected onto a small capture column insulated with OASIS resin (Waters, Milford, MA, USA). Highly polar metabolites and plasma proteins were 
eluted through a coincidence flow detector (Bioscan FlowCount). Less polar metabolites and $\left[{ }^{11} \mathrm{C}\right]$ harmine were then back-flushed onto an HPLC (Phenomenex Luna $\mathrm{C}_{18}, 10 \mu$, $250 \times 4.6 \mathrm{~mm})$.

Frames were acquired as follows: fifteen frames lasting $1 \mathrm{~min}$ each were acquired, followed by 15 frames that were 5 min each. $\left[{ }^{11} \mathrm{C}\right]$ Harmine was of very high radiochemical purity $(98.9 \pm 0.9 \%)$ and high specific activity $(120.7 \pm 72.9$ $\mathrm{GBq} / \mu \mathrm{mol}$ ) at the time of injection. PET images were obtained using a high-resolution research tomograph PET camera (in-plane resolution; full width at half maximum, $3.1 \mathrm{~mm}$; 207 axial sections of $1.2 \mathrm{~mm}$; Siemens Molecular Imaging, Knoxville, TN).

\section{Image Analysis}

MAO-A $\mathrm{V}_{\mathrm{T}}$ represents the total tissue binding of $\left[{ }^{11} \mathrm{C}\right]$ harmine at equilibrium and is highly correlated with MAO-A level, as would be expected since in vivo MAO-A affinity is similar across regions in primates (Bottlaender et al, 2010). Both the unconstrained two-tissue compartment model and Logan model with arterial sampling, for which the underestimate of $\mathrm{V}_{\mathrm{T}}$ is negligible, measure $\mathrm{V}_{\mathrm{T}}$ with high reliability and validity (Ginovart et al, 2006). In the original kinetic modeling of $\left[{ }^{11} \mathrm{C}\right]$ harmine binding to MAO-A, the Pearson's correlation coefficient for MAO-A $\mathrm{V}_{\mathrm{T}}$ values obtained using a two-tissue compartment model and the Logan graphical approach was 0.98 (Ginovart et al, 2006). In the present study, we applied the Logan model (Ginovart et al, 2006; Logan et al, 1990).

The OFC and VS were chosen as the primary ROI, because these regions show molecular abnormalities in ASPD and high psychopathic traits (Buckholtz et al, 2010; Meyer et al, 2008; Rylands et al, 2012) and comprise the neural circuitry underlying pathological impulsivity (Dalley et al, 2011). The boundary of the OFC was defined based on its cytoarchitectural differentiation from adjacent cortical tissue and was mapped onto the external morphology of the cortex (Uylings et al, 2010). The VS was based on the definition provided by Mawlawi et al, 2001. Other secondary ROI were structures previously shown to be abnormal in ASPD and/or those known to have moderate-to-high MAO-A density. These included the dorsal putamen, defined by Mawlawi et al (2001), and prefrontal cortex, anterior cingulate cortex, thalamus, midbrain, and hippocampus, which were derived from a neuroanatomy atlas of structural MRI and postmortem tissue (Duvernoy, 1999), and were used for our previous investigations (Matthews et al, 2014; Soliman et al, 2011). Other subregions of the PFC (dorsolateral prefrontal cortex, ventrolateral prefrontal cortex, and medial prefrontal cortex) were additionally sampled to assess whether the effects observed in the main analyses of the OFC were consistent within these subregions. The boundaries of these additional PFC subregions were defined similarly to the OFC (Rajkowska and Goldman-Rakic, 1995).

The ROI tested in the current investigation were determined by utilizing a semi-automated method, where regions of a template MRI were transformed onto the individual MRI based on a series of transformations and deformations that matched the template image to the individual co-registered MRI followed by segmentation of the individual MRI to select the grey matter voxels, as previously described (Rusjan et al, 2006). Participants received a high-resolution magnetic resonance imaging (MRI) scan to facilitate the ROI analysis (1.5-T GE scanner, fast spoiled gradient echo $\mathrm{T}_{1}$-weighted image; $\mathrm{x}, \mathrm{y}, \mathrm{z}$ voxel dimensions, 0.78, 0.78, and $1.5 \mathrm{~mm}$; GE Medical Systems, Milwaukee, WI; or 3.0-T GE scanner, fast spoiled gradient echo $\mathrm{T}_{1}$-weighted image; $\mathrm{x}, \mathrm{y}, \mathrm{z}$ voxel dimensions, 0.37, 0.37, and $0.90 \mathrm{~mm}$; GE Medical Systems). Previous within-subject cross-validation assessment found that regardless of MRI scanner type, regional MAO-A $\mathrm{V}_{\mathrm{T}}$ values were virtually identical for the main ROIs $(n=6$ subjects; ICC $=0.99-1.0)$.

\section{Measures of Impulsivity in ASPD}

Iowa gambling task. The Iowa Gambling Task (IGT) is a computerized, performance-based card game that indexes choice impulsivity. Participants were instructed to win as much virtual money as possible by selecting cards from any of four decks (A, B, C, or D) one at a time. Decks C and D yield high monetary gains but are accompanied by risk of high losses, whereas decks A and B consistently yield lower gains with the risk of smaller losses. Participants were advised that some decks are more disadvantageous than others and that they could win by avoiding these decks. Twenty trials were administered over five blocks for a total of 100 trials. Highly impulsive groups show the greatest impairment in performance during the latter trials of the IGT (Sweitzer et al, 2008). Accordingly, the net IGT was calculated by subtracting the number of cards selected from disadvantageous decks from the number of cards selected from advantageous decks over the last two blocks: $((\mathrm{C}+\mathrm{D})$ $(\mathrm{A}+\mathrm{B}))$.

NEO Personality inventory-Revised. The NEO Personality Inventory-Revised (NEO PI-R) (Costa, McCrae, 1992) is an extensively validated and reliable self-report measure of 'normal' and abnormal adult personality (Costa and McCrae, 1992) that provides norm-referenced test scores for broadbased dimensional personality domains and traits, including impulsivity. All participants completed the NEO PI-R.

Psychopathy Checklist-Revised. A trained forensic psychiatrist (NJK) administered the Psychopathy ChecklistRevised (PCL-R) (Hare, 2003) to the ASPD participants. The PCL-R evaluates 20 interpersonal, affective, and behavioral traits that relate to the personality disorder of psychopathy, including impulsivity. Items were scored from 0 to 2 based on the presence or absence of each trait $(0=$ no; $1=$ maybe; $2=$ yes) using information obtained during the clinical interview and official criminal records.

\section{Statistical Analysis}

Multivariate analysis of variance (MANOVA) was used to test our hypothesis that OFC and VS MAO-A $\mathrm{V}_{\mathrm{T}}$ would be lower in ASPD versus controls. To further characterize the comparison of ASPD and control subjects, MANOVA was applied to assess the group effect on MAO-A $V_{T}$ in the PFC, VS, anterior cingulate cortex, dorsal putamen, thalamus, hippocampus, and midbrain. A separate MANOVA was conducted on the PFC subregions to test whether the anticipated effect of diagnosis was widespread 
in the PFC. To test the hypothesis that OFC and VS MAO-A $\mathrm{V}_{\mathrm{T}}$ would be inversely related to impulsivity, Pearson's correlation coefficients were calculated.

\section{RESULTS}

\section{Subject Characteristics}

Participants were aged 18-49 years. The ASPD group reported significantly greater impulsivity and more conduct disorder symptoms compared with the control group (see Table 1).

\section{Difference in MAO-A $V_{T}$ Between ASPD Group and Control Subjects}

The main finding is that MAO-A $\mathrm{V}_{\mathrm{T}}$ was significantly lower in ASPD versus controls, on average by $19.3 \%$ and $18.8 \%$ in the VS and OFC, respectively (MANOVA group effect: $\left.\mathrm{F}_{2,33}=6.8, P=0.003\right)$. Significant univariate effects were also detected in the VS $\left(\mathrm{F}_{1,34}=12.9, P=0.001\right)$ and OFC $\left(\mathrm{F}_{1,34}=12.6, P=0.001\right.$; See Figure 1). Results did not change when the control participant with the highest MAO-A $\mathrm{V}_{\mathrm{T}}$ values was removed from the analysis (MANOVA group effect: $\mathrm{F}_{2,32}=6.2, \quad P=0.005$; univariate effect of VS: $\mathrm{F}_{1,33}=11.3, P=0.002$; univariate effect of OFC: $\mathrm{F}_{1,33}=11.7$, $P=0.002)$. A separate MANOVA that compared ASPD subjects $(n=18)$ with the controls lacking $\mathrm{AD}(n=9)$ revealed lower OFC and VS MAO-A $\mathrm{V}_{\mathrm{T}}$ in the ASPD group $\left(\mathrm{F}_{2,24}=3.8, \quad P=0.036\right)$. Another MANOVA comparing the subgroup of ASPD subjects with $\mathrm{AD}(n=9)$ with all control subjects $(n=18)$ additionally found that OFC and VS MAO-A $\mathrm{V}_{\mathrm{T}}$ were lower in the ASPD subgroup (MANOVA group effect: $\mathrm{F}_{2,24}=6.0, P=0.008$ ).

MAO-A $V_{\mathrm{T}}$ was also lower in all of the main brain regions analyzed for the ASPD participants $(n=18)$ compared with controls $(n=18) \quad$ (MANOVA group effect: $\mathrm{F}_{7,28}=2.7$, $P=0.029$ ), with significant univariate effects detected in all regions $\left(\mathrm{F}_{1,34}=4.2\right.$ to $12.9, \quad P$-values $=0.048$ to 0.001$)$. In addition, subregions of the PFC were assessed with similar results (MANOVA group effect: $\mathrm{F}_{4,31}=3.2$, $P=0.025$ ). Post hoc tests revealed that the group difference was significant for each prefrontal region (See Table 2).

In a subset of the entire sample that included 10 ASPD and 10 control participants, MAO-A $V_{T}$ values for the PFC were compared using the Logan analysis and two-tissue compartment model. Results were highly correlated $(r=0.996$, $P<0.0001)$ and similar, with an underestimate of $4 \%$ in MAO-A $\mathrm{V}_{\mathrm{T}}$ using the Logan analysis.

\section{Relationship Between VS and OFC MAO-A $V_{T}$ and Measures of Impulsivity in ASPD Subjects}

In the ASPD subjects, VS MAO-A $\mathrm{V}_{\mathrm{T}}$ was negatively correlated with IGT performance $(r=-0.52, P=0.034)$. That is, lower VS MAO-A $V_{T}$ was associated with more risky and impulsive decision making. VS MAO-A $\mathrm{V}_{\mathrm{T}}$ also showed an inverse relationship with self-reported impulsivity on the NEO PI-R $(r=-0.50, P=0.034)$. ASPD subjects who were rated the most impulsive on the PCL-R had the lowest VS MAO-A $\mathrm{V}_{\mathrm{T}}\left(t_{16}=2.8, P=0.013\right.$; see Figure 2$)$. No significant relationships were detected in the ASPD sample between
Table I Demographic and Clinical Characteristics

\begin{tabular}{lcc}
\hline Characteristics $^{\mathbf{a}}$ & $\begin{array}{c}\text { ASPD } \\
(\boldsymbol{n}=\mathbf{1 8})\end{array}$ & $\begin{array}{c}\text { Controls } \\
(\boldsymbol{n}=\mathbf{1 8})\end{array}$ \\
\hline Age $^{\mathrm{b}}$ & $36.2 \pm 9.4$ & $36.4 \pm 8.9$ \\
$\%$ Male & 100 & 100
\end{tabular}

Comorbid substance use

$\begin{array}{lrr}\text { \% Smoking } & 0 & 0 \\ \text { \% Alcohol dependence } & 50 & 50\end{array}$

\section{Medications}

\% Taking psychotropic medications

0

0

Dysphoria

17-item HDRS scorec

$3.6 \pm 2.8 \quad 1.9 \pm 2.0$

Impulsivity (self-reported)

$59.2 \pm 12.4^{*} \quad 50.4 \pm 12.6$

Conduct disordered behavior

Number of conduct disorder symptoms ${ }^{c} \quad 7.9 \pm 0.4^{* *} \quad 0.4 \pm 0.9$

Psychopathy

PCL-R total score

PCL-R factor I score

$26.4 \pm 6.8$

$\mathrm{NA}^{\mathrm{d}}$

PCL-R factor 2 score

$9.4 \pm 3.3$

NA

$14.8 \pm 3.9$

NA

Abbreviations: ASPD, antisocial personality disorder; HDRS, Hamilton Depression Rating Scale; NA, not available; NEO PI-R, NEO Personality InventoryRevised; PCL-R, Psychopathy Checklist-Revised.

${ }^{a} V$ alues are expressed as mean \pm s.d., except where indicated.

bindependent samples t-test.

cMann-Whitney U-test.

${ }^{\mathrm{d}}$ For individuals with no history of ASPD or conduct disorder, the average total PCL-R score is $<8$ (Hare, 2003); $* P<0.05$, two-tailed; $* * P<0.001$, two-tailed.

OFC MAO-A $V_{\mathrm{T}}$ and PCL-R impulsivity $\left(t_{16}=1.7, P=0.11\right)$, OFC MAO-A $\mathrm{V}_{\mathrm{T}}$ and IGT performance $(r=0.07, P=0.80)$, or OFC MAO-A $\mathrm{V}_{\mathrm{T}}$ and NEO PI-R impulsivity $(r=-0.02$, $P=0.94)$. No significant relationships were detected between MAO-A binding and impulsivity measures for any of the other regions tested, except that the dorsal putamen MAO-A $V_{T}$ was lower in the ASPD subjects rated more impulsive on the PCL-R compared with those rated less impulsive $\left(19.7 \pm 1.9\right.$ vs $\left.23.3 \pm 1.3 ; t_{16}=2.9, P=0.01\right)$.

There was no relationship between MAO-A $\mathrm{V}_{\mathrm{T}}$, prior medication exposure, or class of prior medication exposure in the ASPD and control groups. When we excluded from the analyses the ASPD participant who had used benzodiazepines 2 months prior to his involvement in the study, all significant group and correlational findings persisted.

\section{DISCUSSION}

This study is the first investigation of MAO-A brain level in impulsive and violent offenders with a DSM-IV diagnosis of ASPD. Consistent with our main hypotheses, we found that OFC and VS MAO-A $V_{T}$ were lower in ASPD and that 


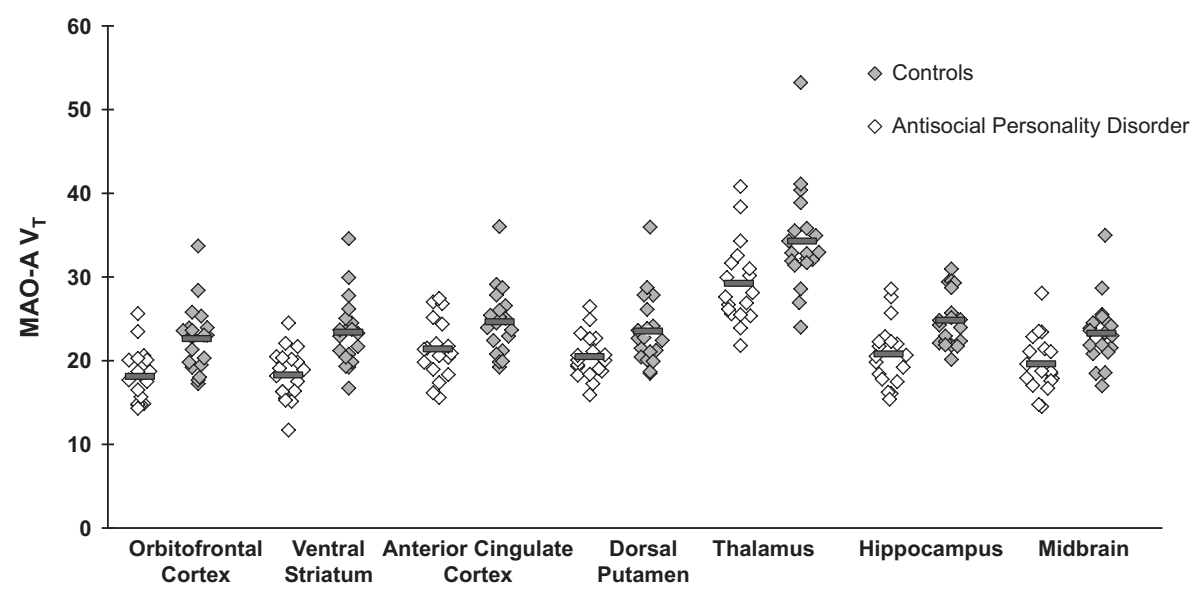

Figure I Lower MAO-A $V_{T}$ in Antisocial Personality Disorder. Multivariate analysis of variance (MANOVA) indicates that antisocial personality disorder (ASPD) was associated with lower MAO-A $V_{T}$ (monoamine oxidase-A total distribution volume) in orbitofrontal cortex and ventral striatum compared with controls (MANOVA group effect: $F 2,33=6.8, P=0.003$ ). Controls contained a mix of participants with no psychiatric comorbidity $(n=9)$ and participants with alcohol dependence and no other psychiatric comorbidity $(n=9)$ to optimally match with ASPD participants, nine of whom also had comorbid alcohol dependence. There was also an effect of diagnosis on MAO-A $V_{T}$ across all brain regions indicated above (MANOVA group effect: $\left.F_{7,28}=2.8, P=0.022\right)$. Horizontal bars indicate mean MAO-A $V_{T}$ values. Differences remained significant when the control subject with the highest $M A O-A V_{T}$ values was removed from the analyses.

Table 2 Comparison of MAO-A $V_{T}$ in ASPD Versus Controls for Prefrontal Cortex Subregions

\begin{tabular}{lcccc}
\hline & $\begin{array}{c}\text { ASPD } \\
\text { MAO-A V }\end{array}$ & $\begin{array}{c}\text { Control } \\
\text { MAO-A V }\end{array}$ & ANOVA & P-value \\
\hline $\begin{array}{l}\text { Region } \\
\text { Orbitofrontal cortex }\end{array}$ & $18.1 \pm 3.2$ & $22.3 \pm 3.9$ & $F_{1,34}=12.6$ & 0.001 \\
$\begin{array}{l}\text { Dorsolateral } \\
\text { prefrontal cortex }\end{array}$ & $20.1 \pm 2.9$ & $22.9 \pm 3.9$ & $F_{1,34}=6.0$ & 0.020 \\
$\begin{array}{l}\text { Ventrolateral } \\
\text { prefrontal cortex }\end{array}$ & $19.4 \pm 3.2$ & $23.3 \pm 4.4$ & $F_{1,34}=9.3$ & 0.004 \\
$\begin{array}{l}\text { Medial prefrontal } \\
\text { cortex }\end{array}$ & $21.6 \pm 3.2$ & $24.5 \pm 3.7$ & $F_{1,34}=6.6$ & 0.015 \\
\hline
\end{tabular}

Abbreviations: ANOVA, analysis of variance; $\mathrm{ASPD}$, antisocial personality disorder; $M A O-A V_{T}$, monoamine oxidase-A total distribution volume. Multivariate analysis of variance (MANOVA) indicates that antisocial personality disorder was associated with lower MAO-A $\bigvee_{T}$ in all four subregions of the prefrontal cortex compared with controls (MANOVA group effect: $\left.F_{4,31}=3.2, P=0.025\right)$. Individual ANOVA results are also presented for each subregion.

behavioral, self-report, and clinically rated measures of impulsivity were all negatively associated with VS MAO-A $\mathrm{V}_{\mathrm{T}}$. In contrast to previous PET research examining brain MAO-A levels in healthy humans with relatively low trait aggression and impulsivity, the present investigation has the advantage of studying a clinical population with pathological aggression and impulsivity. The results of the present study have important implications for understanding the molecular underpinnings of ASPD and selecting preclinical models to represent ASPD. Our findings also suggest a neuromodulatory role of MAO-A on the impulsive and rewardseeking behavior that typifies ASPD.
Our main finding is that low OFC and VS MAO-A $\mathrm{V}_{\mathrm{T}}$ was associated with a disorder characterized by pathological levels of impulsivity and aggression. There are two conceptual models relating lower MAO-A levels to impulsiveaggressive behavior in humans. One involves the very infrequent event of completely deficient MAO-A due to genetic disruption of the MAO-A gene that was identified in impulsively aggressive males from a single Dutch family (Brunner et al, 1993). However, subsequent efforts to isolate this mutation in targeted, antisocial populations have been unsuccessful (Schuback et al, 1999). To the best of our knowledge, there have been no additional human cases of the non-conservative cytosine to thymine mutation in exon 8 of the MAO-A gene documented in the literature. A second model implicates relative brain MAO-A deficiency as a more common event and potential neuropathological substrate of aberrant impulsivity and aggression. Although this study cannot exclude the possibility that other mutations of a similar magnitude effect occur in ASPD, it does suggest that low brain MAO-A levels are common in ASPD and that low brain MAO-A $\mathrm{V}_{\mathrm{T}}$ is a viable target to pursue in therapeutic or preventative strategies.

Our results also have significant ramifications for the relevance of MAO-A knockout strategies to model ASPD and clinical level aggression and impulsivity in humans. For example, in addition to manifesting extreme impulsive aggression (Cases et al, 1995; Godar et al, 2011; Popova et al, 2001; Scott et al, 2008), MAO-A knockouts also exhibit cognitive and physiological responses characteristic of ASPD with high psychopathic traits, such as decreased startle reflex (Popova et al, 2001), reduced anxiety, impaired risk assessment (Godar et al, 2011), and attenuated stress reaction (Popova et al, 2006). Although there are several manipulations that can lead to impulsive-aggressive behavior in rodents, a critical issue is whether such models actually translate to the human clinical phenotype. In some cases, the 
a

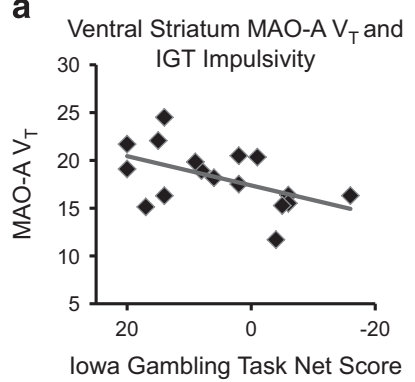

b

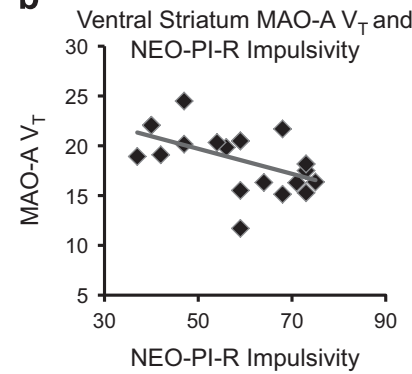

C

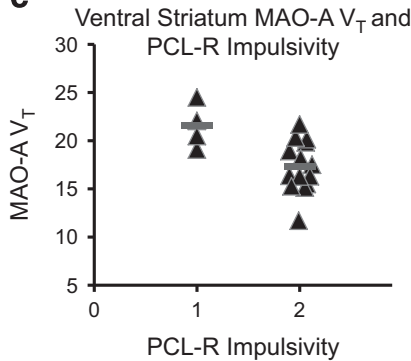

Figure 2 Ventral Striatum MAO-A $V_{T}$ is Negatively Associated with Measures of Impulsivity in ASPD. (a) Ventral striatum MAO-A $V_{T}$ is negatively correlated with risky performance during the latter half of the IGT Task (Pearson's $r=-0.52, P=0.034$ ). (b) Ventral striatum MAO-A $V_{\mathrm{T}}$ is negatively correlated with self-reported impulsivity on the NEO PI-R (Pearson's $r=-0.50, P=0.034$ ). Note that $x$ axis depicts T-scores (a similar significant relationship was found with raw scores). (c) ASPD subjects rated the most impulsive on the PCL-R (PCL-R score $=2)$ had lower ventral striatum MAO- $V_{T}$ than subjects rated less impulsive on the PCL-R (PCL-R score $=1$ ) (means (horizontal bars): 17.4 vs $21.5 ; t_{16}=2.8, P=0.013$ ). Note that columns in (c) are labeled according to PCL-R impulsivity score. MAO$A V_{T}$, monoamine oxidase-A total distribution volume; IGT, lowa Gambling Task; NEO PI-R, NEO Personality Inventory-Revised; ASPD, antisocial personality disorder; PCL-R, Psychopathy Checklist-Revised; ANOVA, analysis of variance.

phenotypes do not match. For instance, $5-\mathrm{HT}_{1 \mathrm{~B}}$ knockout conditions are associated with increased impulsive violence in mice (Saudou et al, 1994), but $5-\mathrm{HT}_{1 \mathrm{~B}}$ receptor binding in postmortem prefrontal cortex does not differ between pathologically aggressive and healthy individuals (Huang et al, 1999). Moreover, molecular imaging studies find a relationship between lower $5-\mathrm{HT}_{1 \mathrm{~B}}$ receptor expression and internalizing conditions, such as posttraumatic stress disorder and major depressive disorder, that are not, on average, associated with high aggression or impulsivity (Murrough et al, 2011a, b). By contrast, the consistency in phenotype between the MAO-A knockout and ASPD with high psychopathic traits (eg, increased aggression, high impulsivity, low anxiety, fearless dominance, and low stress hormones) suggests that the MAO-A knockout is an important model for understanding the pathophysiology of ASPD.

Although a previous investigation of healthy humans reported an association of impulsivity-related measures with OFC MAO-A level, this study differed from the present one in that it tested a non-pathological sample of subjects with normal personality measures (Soliman et al, 2011). We interpret our data to mean that MAO-A level in the VS may be more relevant to conditions of pathological impulsivity. It is possible that the neurobiological processes in the VS relating to extreme impulsivity are more affected by lower MAO-A level.

We actually found that VS MAO-A $V_{T}$ in ASPD was negatively correlated with several measures of impulsivity, including a performance-based assessment and a validated self-report measure, and these results have implications for understanding the potential neuromodulatory influence of MAO-A on impulsive and reward-seeking behavior. Heightened behavioral sensitivity to reward versus punishment is a core feature of ASPD and psychopathy (Mitchell et al, 2002; Petry, 2002) underlying the reckless and impulsive behavior of these conditions (Blair, 2008). Mounting evidence suggests that exaggerated dopamine response to highly salient stimuli increases vulnerability to impulsive and reward-seeking behaviors (Leyton and Vezina, 2014). One model of impulsivity in individuals with high antisocialimpulsive psychopathic traits posits that neurochemical hypersensitivity of the mesolimbic dopamine system to rewarding stimuli underlies expression of impulsive and socially deviant behavior (Buckholtz et al, 2010). Consistent with this hypothesis, a recent molecular imaging study found that greater VS $6-\left[{ }^{18} \mathrm{~F}\right]$ fluoro-L-DOPA influx constant, a measure of dopamine synthesis capacity and vesicular storage capacity, was associated with greater behavioral disinhibition (Lawrence and Brooks, 2014). Thus, it has been proposed that individuals at high risk for externalizing conditions have larger amounts of presynaptic dopamine (Lawrence and Brooks, 2014). As dopamine is a high-affinity substrate for MAO-A in humans (O'Carroll et al, 1983) and MAO-A inhibition potentiates striatal dopamine efflux (Finberg et al, 1995), we interpret the association between lower VS MAO-A $\mathrm{V}_{\mathrm{T}}$ and increased impulsivity as supportive of the model linking greater VS presynaptic dopamine efflux and/or reward-based dopamine release to high impulsivity and externalizing behaviors.

Although the present study has the advantage of measuring an index of MAO-A density in vivo, it has disadvantages inherent to PET neuroimaging. The resolution of PET precludes investigation of the cellular specificity of changes in MAO-A, which does not allow differentiation of MAO-A between glia and neurons. Another limitation is that MAO-A $\mathrm{V}_{\mathrm{T}}$, while robustly measured with $\left[{ }^{11} \mathrm{C}\right]$ harmine PET, reflects total MAO-A binding. However, as free and nonspecific binding account for only $15 \%$ of MAO-A $V_{T}$, differences in the measure primarily reflect changes in specific MAO-A binding (Ginovart et al, 2006). Finally, similar to the overwhelming majority of studies of ASPD and violent offenders, our sample was limited to males, which may be justified on the basis that ASPD is 5-7 times more common in men than women (Hamdi and Iacono, 2014).

In summary, we found that highly impulsive, violent males with ASPD had lower MAO-A $\mathrm{V}_{\mathrm{T}}$ in the OFC and VS. These results suggest that lower MAO-A in these regions is a common occurrence in ASPD and not limited to rare mutations. Our results also highlight the salience of preclinical models exhibiting low brain levels of MAO-A for understanding this clinical condition by demonstrating, to the best of our knowledge, the first clear link between a pathological marker in preclinical investigations of aggression with the same marker in human ASPD. Lower VS MAO-A levels were additionally associated with greater impulsivity, which, given the role of MAO-A in modulating dopamine efflux, suggests 
greater complexity to the model linking elevated VS dopamine release to rewarding stimuli in externalizing disorders.

\section{FUNDING AND DISCLOSURE}

Drs Meyer, Wilson, and Houle have received operating grant funds for other studies from Eli-Lilly, GlaxoSmithKline, Bristol Myers Squibb, Lundbeck, Janssen, and SK Life Sciences in the past 5 years. Dr Meyer has consulted to several of these companies as well as Takeda, Sepracor, Trius, Mylan and Teva. Dr Links received an honorarium from Lundbeck within the past 5 years. None of these companies participated in the design or execution of this study or in writing the manuscript. All other authors report no disclosures.

\section{ACKNOWLEDGMENTS}

This research received project support from the Canadian Institutes of Health Research, Physicians' Services Incorporated Foundation, and American Psychiatric Institute for Research and Education. These organizations did not participate in the design or execution of this study or the writing of the manuscript. We also thank the Campbell Family Mental Health Research Institute; technicians Alvina $\mathrm{Ng}$ and Laura Nguyen; chemistry staff Jun Parkes, Armando Garcia, Winston Stableford, and Min Wong; engineers Terry Bell and Ted Harris-Brandts; and students Charis Kellow and Jalpa Patel for their assistance with this project. Dr Meyer takes responsibility for the integrity of the data and the accuracy of the data analysis; all authors had full access to all data in the study.

\section{REFERENCES}

Alia-Klein N, Goldstein RZ, Kriplani A, Logan J, Tomasi D, Williams B et al (2008). Brain monoamine oxidase A activity predicts trait aggression. J Neurosci 28: 5099-5104.

Blair RJ (2004). The roles of orbital frontal cortex in the modulation of antisocial behavior. Brain Cogn 55: 198-208.

Blair RJ (2008). The amygdala and ventromedial prefrontal cortex: functional contributions and dysfunction in psychopathy. Philos Trans $R$ Soc Lond B Biol Sci 363: 2557-2565.

Bortolato M, Chen K, Shih JC (2008). Monoamine oxidase inactivation: from pathophysiology to therapeutics. Adv Drug Deliv Rev 60: 1527-1533.

Bottlaender M, Valette H, Delforge J, Saba W, Guenther I, Curet O et al (2010). In vivo quantification of monoamine oxidase $\mathrm{A}$ in baboon brain: a PET study using [(11)C]befloxatone and the multi-injection approach. J Cereb Blood Flow Metab 30: 792-800.

Brunner HG, Nelen M, Breakefield XO, Ropers HH, van Oost BA (1993). Abnormal behavior associated with a point mutation in the structural gene for monoamine oxidase A. Science 262: 578-580.

Buckholtz JW, Treadway MT, Cowan RL, Woodward ND, Benning $\mathrm{SD}$, Li R et al (2010). Mesolimbic dopamine reward system hypersensitivity in individuals with psychopathic traits. Nat Neurosci 13: 419-421.

Cases O, Seif I, Grimsby J, Gaspar P, Chen K, Pournin S et al (1995). Aggressive behavior and altered amounts of brain serotonin and norepinephrine in mice lacking MAOA. Science 268: 1763-1766.
Caspi A, McClay J, Moffitt TE, Mill J, Martin J, Craig IW et al (2002). Role of genotype in the cycle of violence in maltreated children. Science 297: 851-854.

Costa PT Jr., McCrae RR (1992). Revised NEO Personality Inventory (NEO-PI-R) and NEO Five-Factor Inventory (NEO-FFI). Psychological Assessment Resources: Odessa, FL.

Dalley JW, Everitt BJ, Robbins TW (2011). Impulsivity, compulsivity, and top-down cognitive control. Neuron 69: 680-694.

Duvernoy H (1999). The Human Brain: Surface, Blood Supply and Three Dimensional Section Anatomy. SpringerWien: New York, NY.

Finberg JP, Wang J, Goldstein DS, Kopin IJ, Bankiewicz KS (1995). Influence of selective inhibition of monoamine oxidase A or B on striatal metabolism of L-DOPA in hemiparkinsonian rats. J Neurochem 65: 1213-1220.

First MB, Gibbon M, Spitzer RL, Williams JBW, Benjamin LS (1997). Structured Clinical Interview for DSM-IV Axis II Personality Disorders, (SCID-II). American Psychiatric Press, Inc.: Washington, DC.

First MB, Spitzer RL, Gibbon M, Williams JBW (2002). Structured Clinical Interview for DSM-IV-TR Axis I Disorders, Research Version, Patient Edition (SCID-I/P). Version 2, Biometrics Research, New York State Psychiatric Institute: New York, NY.

Ginovart N, Meyer JH, Boovariwala A, Hussey D, Rabiner EA, Houle $S$ et al (2006). Positron emission tomography quantification of [11C]-harmine binding to monoamine oxidase-A in the human brain. J Cereb Blood Flow Metab 26: 330-344.

Glenn AL, Yang Y (2012). The potential role of the striatum in antisocial behavior and psychopathy. Biol Psychiatry 72: 817-822.

Godar SC, Bortolato M, Frau R, Dousti M, Chen K, Shih JC (2011). Maladaptive defensive behaviours in monoamine oxidase A-deficient mice. Int J Neuropsychopharmacol 14: 1195-1207.

Hamdi NR, Iacono WG (2014). Lifetime prevalence and co-morbidity of externalizing disorders and depression in prospective assessment. Psychol Med 44: 315-324.

Hare R (2003). Hare Psychopathy Checklist-Revised. 2nd Edn. MultiHealth Systems: Toronto, Canada.

Hilton J, Yokoi F, Dannals RF, Ravert HT, Szabo Z, Wong DF (2000). Column-switching HPLC for the analysis of plasma in PET imaging studies. Nucl Med Biol 27: 627-630.

Huang YY, Grailhe R, Arango V, Hen R, Mann JJ (1999). Relationship of psychopathology to the human serotonin1B genotype and receptor binding kinetics in postmortem brain tissue. Neuropsychopharmacology 21: 238-246.

Lawrence AD, Brooks DJ (2014). Ventral striatal dopamine synthesis capacity is associated with individual differences in behavioral disinhibition. Front Behav Neurosci 8: 86 .

Leyton M, Vezina P (2014). Dopamine ups and downs in vulnerability to addictions: a neurodevelopmental model. Trends Pharmacol Sci 35: 268-276.

Logan J, Fowler JS, Volkow ND, Wolf AP, Dewey SL, Schlyer DJ et al (1990). Graphical analysis of reversible radioligand binding from time-activity measurements applied to [N-11C-methyl](-)-cocaine PET studies in human subjects. J Cereb Blood Flow Metab 10: 740-747.

Matthews BA, Kish SJ, Xu X, Boileau I, Rusjan PM, Wilson AA et al (2014). Greater monoamine oxidase A binding in alcohol dependence. Biol psychiatry 75: 756-764.

Mawlawi O, Martinez D, Slifstein M, Broft A, Chatterjee R, Hwang DR et al (2001). Imaging human mesolimbic dopamine transmission with positron emission tomography: I. Accuracy and precision of $\mathrm{D}(2)$ receptor parameter measurements in ventral striatum. J Cereb Blood Flow Metab 21: 1034-1057.

Mejia JM, Ervin FR, Baker GB, Palmour RM (2002). Monoamine oxidase inhibition during brain development induces pathological aggressive behavior in mice. Biol Psychiatry 52: 811-821.

Meyer JH, Wilson AA, Rusjan P, Clark M, Houle S, Woodside S et al (2008). Serotonin2A receptor binding potential in people 
with aggressive and violent behaviour. J Psychiatry Neurosci 33: 499-508.

Mitchell DG, Colledge E, Leonard A, Blair RJ (2002). Risky decisions and response reversal: is there evidence of orbitofrontal cortex dysfunction in psychopathic individuals? Neuropsychologia 40: 2013-2022.

Moffitt TE, Caspi A, Harrington H, Milne BJ (2002). Males on the life-course-persistent and adolescence-limited antisocial pathways: follow-up at age 26 years. Dev Psychopathol 14: 179-207.

Murrough JW, Czermak C, Henry S, Nabulsi N, Gallezot JD, Gueorguieva R et al (2011a). The effect of early trauma exposure on serotonin type $1 \mathrm{~B}$ receptor expression revealed by reduced selective radioligand binding. Arch Gen Psychiatry 68: 892-900.

Murrough JW, Henry S, Hu J, Gallezot JD, Planeta-Wilson B, Neumaier JF et al (2011b). Reduced ventral striatal/ventral pallidal serotonin1B receptor binding potential in major depressive disorder. Psychopharmacology (Berl) 213: 547-553.

O'Carroll AM, Fowler CJ, Phillips JP, Tobbia I, Tipton KF (1983). The deamination of dopamine by human brain monoamine oxidase. Specificity for the two enzyme forms in seven brain regions. Naunyn Schmiedebergs Arch Pharmacol 322: 198-202.

Petry NM (2002). Discounting of delayed rewards in substance abusers: relationship to antisocial personality disorder. Psychopharmacology (Berl) 162: 425-432.

Popova NK, Maslova LN, Morosova EA, Bulygina VV, Seif I (2006). MAO A knockout attenuates adrenocortical response to various kinds of stress. Psychoneuroendocrinology 31: 179-186.

Popova NK, Skrinskaya YA, Amstislavskaya TG, Vishnivetskaya GB, Seif I, de Meier E (2001). Behavioral characteristics of mice with genetic knockout of monoamine oxidase type A. Neurosci Behav Physiol 31: 597-602.

Rajkowska G, Goldman-Rakic PS (1995). Cytoarchitectonic definition of prefrontal areas in the normal human cortex: I. Remapping of areas 9 and 46 using quantitative criteria. Cereb cortex 5: 307-322.

Rubio G, Jimenez M, Rodriguez-Jimenez R, Martinez I, Avila C, Ferre $\mathrm{F}$ et al (2008). The role of behavioral impulsivity in the development of alcohol dependence: a 4-year follow-up study. Alcohol Clin Exp Res 32: 1681-1687.

Rusjan P, Mamo D, Ginovart N, Hussey D, Vitcu I, Yasuno F et al (2006). An automated method for the extraction of regional data from PET images. Psychiatry Res 147: 79-89.
Rylands AJ, Hinz R, Jones M, Holmes SE, Feldmann M, Brown G et al (2012). Pre- and postsynaptic serotonergic differences in males with extreme levels of impulsive aggression without callous unemotional traits: a positron emission tomography study using (11)C-DASB and (11)C-MDL100907. Biol Psychiatry 72: 1004-1011.

Saudou F, Amara DA, Dierich A, LeMeur M, Ramboz S, Segu L et al (1994). Enhanced aggressive behavior in mice lacking 5-HT1B receptor. Science 265: 1875-1878.

Saura J, Kettler R, Da Prada M, Richards JG (1992). Quantitative enzyme radioautography with 3H-Ro 41-1049 and 3H-Ro 19-6327 in vitro: localization and abundance of MAO-A and $\mathrm{MAO}-\mathrm{B}$ in rat CNS, peripheral organs, and human brain. J Neurosci 12: 1977-1999.

Schuback DE, Mulligan EL, Sims KB, Tivol EA, Greenberg BD, Chang SF et al (1999). Screen for MAOA mutations in target human groups. Am J Med Genet 88: 25-28.

Scott AL, Bortolato M, Chen K, Shih JC (2008). Novel monoamine oxidase A knock out mice with human-like spontaneous mutation. Neuroreport 19: 739-743.

Soliman A, Bagby RM, Wilson AA, Miler L, Clark M, Rusjan P et al (2011). Relationship of monoamine oxidase A binding to adaptive and maladaptive personality traits. Psychol Med 41: 1051-1060.

Son SY, Ma J, Kondou Y, Yoshimura M, Yamashita E, Tsukihara T (2008). Structure of human monoamine oxidase A at 2.2-A resolution: the control of opening the entry for substrates/ inhibitors. Proc Natl Acad Sci USA 105: 5739-5744.

Swann AC, Lijffijt M, Lane SD, Steinberg JL, Moeller FG (2009). Trait impulsivity and response inhibition in antisocial personality disorder. J Psychiatr Res 43: 1057-1063.

Sweitzer MM, Allen PA, Kaut KP (2008). Relation of individual differences in impulsivity to nonclinical emotional decision making. J Int Neuropsychol Soc 14: 878-882.

Uylings HB, Sanz-Arigita EJ, de Vos K, Pool CW, Evers P, Rajkowska G (2010). 3-D cytoarchitectonic parcellation of human orbitofrontal cortex correlation with postmortem MRI. Psychiatry Res 183: 1-20.

Zhou J, Witt K, Zhang Y, Chen C, Qiu C, Cao L et al (2014). Anxiety, depression, impulsivity and substance misuse in violent and non-violent adolescent boys in detention in China. Psychiatry Res 216: 379-384. 